\title{
A comparative study on quality parameters of pumpkin, melon and sunflower oils during thermal treatment
}

\author{
Zhana Petkova* and Ginka Antova \\ University of Plovdiv 'Paisii Hilendarski', Department of Chemical Technology, 24, Tzar Asen Street, 4000 Plovdiv, Bulgaria
}

Received 31 January 2019 - Accepted 21 May 2019

\begin{abstract}
Current paper reveals the impact of thermal treatment on the quality of two seed oils - pumpkin and melon compared to the quality of the most used oil-sunflower oil. Conventional and microwave heating were used for processing the oils. The duration of the thermal treatment was 9,12 and 18 min for the conventional heating. The microwave heating was performed with two microwave powers of the equipment $(600 \mathrm{~W}$ and $900 \mathrm{~W})$ for 3, 6, 9 and $12 \mathrm{~min}$. At every stage of the thermal processing were determined acid and peroxide value, the absorbance of the oils at 232 and $268 \mathrm{~nm}$, tocopherol and fatty acid composition. It was observed that the degree of oxidation of the examined oils during microwave and conventional heating increased with the duration of the thermal process and the power of the microwaves. Also, the two methods of heating had a little impact on the processes leading to the formation of free fatty acids. Total tocopherols of the melon seed oil were more stable to thermal treatment. The amount of linoleic acid decreased in the pumpkin and sunflower oils during microwave treatment, while that of oleic and palmitic acid relatively increased. The biggest change in the fatty acid composition of both oils was found during microwave heating at $900 \mathrm{~W}$. The changes in fatty acid composition of thermally treated melon seed oil were insignificant. Overall, melon seed oil was observed to be more thermally stable than pumpkin and sunflower oils.
\end{abstract}

Keywords: pumpkin seed oil / melon seed oil / sunflower oil / thermal treatment / quality of oils

\section{Introduction}

Conventional heating is the most commonly used method in the world for food preparation. The thermal treatment is carried out at high temperature and in the presence of moisture and atmospheric oxygen, whereby the processes of oxidation and hydrolysis of the oils are activated. These reactions lead to a change in the functional, sensory and nutritional qualities of the processed foods and have great impact on human health. In the heat treatment of food products, microwave heating is also widely used (Lukešova et al., 2009). It is more efficient method and reduces the cooking time of the products. The application of microwave processing is increasing and therefore the attention of scientists is attracted to its impact on food products and their ingredients. However, the effect of microwave heating on the nutritional properties of the lipid fraction is insufficiently studied. During the heating of the oils are formed first primary products of oxidation (peroxides and hydroperoxides) and after that - secondary products such as aldehydes, ketones, etc. The deterioration of the vegetable oils

*Correspondance: zhanapetkova@uni-plovdiv.net and animal fats also depends on the content of the polyunsaturated fatty acids and the amount of free fatty acids increases during the microwave heating (Yoshida et al., 1990; Yoshida et al., 1992). According to Yoshida and Kajimoto (1989), total tocopherol content gradually decreases during the microwave treatment.

Although, some previous studies reveal the impact of thermal treatment of some common used plant oils (such as sunflower, soybean, peanut, rapeseed, corn, canola, etc.) (Lukešova et al., 2009; Vieira and Regitano-D'Arce, 1998; Hassanein et al., 2003), there is no information about the changes that occurs in melon seed oil subjected to conventional and microwave heating and the data about the pumpkin seed oil is rather scarce because both oils have limited application for cooking. Pumpkin and melon seeds have considerably high oil content over $50 \%$ for pumpkin seeds and $41-45 \%$ for melon seeds (Jiao et al., 2014; Petkova and Antova, 2015), which is a reason for their use as a rich oil source. The oils are abundant in essential fatty acids (such as linoleic and oleic acids) and tocopherols (mainly $\gamma$-tocopherol) (Jiao et al., 2014; Rabrenović et al., 2014; Petkova and Antova, 2015; Murkovic et al., 2004; Aktas et al., 2018). Though pumpkin and melon seed oils are rich of unsaturated fatty acids, they are reported to 
have relatively high oxidative stability (the induction time of pumpkin and melon seed oils is $12.8-25.7 \mathrm{~h}$ and $4.28-5.9 \mathrm{~h}$, respectively) (Szterk et al., 2010; Vidrih et al., 2010; Azhari et al., 2014; Mariod and Matthäus, 2008).

Jiao et al. (2014) performed a green microwave-assisted aqueous enzymatic extraction method for obtaining pumpkin seed oil and reported that this oil exhibited better oxidation stability compared to the Soxhlet-extracted oil. Szterk et al. (2010) also reveal that pumpkin seed oil is more oxidatively stable than rapeseed, linseed, primrose, camelina and borage oils, due to the presence of considerable amount of oleic acid and low amount of linolenic acid. This observation leads to the hypothesis that pumpkin and melon seed oils can be more stable when they are subjected to heating than some other oils used for cooking. Therefore, the aim of the present study was to examine the effect of microwave and conventional processing on pumpkin and melon seed oils. For that reason, have to be monitored the changes in the main physicochemical parameters (acid and peroxide value, the absorbance of the oils at 232 and $268 \mathrm{~nm}$ ) as well as in the tocopherol and fatty acid composition of the oils, which were treated by conventional and microwave heating. The obtained results were compared to these of the most commonly used for cooking in Bulgaria sunflower oil in order to be concluded whether pumpkin and melon seed oils were suitable for thermal treatment.

\section{Materials and methods}

\subsection{Materials}

Pumpkin, melon and sunflower seeds were purchased by a specialized seed trading shop (Plovdiv, Bulgaria). The moisture content of the seeds was determined according to AOAC (2016) and was found to be as follows: $5.1 \%$ for pumpkin seeds, $6.0 \%$ for melon seeds and $6.5 \%$ for sunflower seeds. The oils were extracted from the seeds using Soxhlet extraction with hexane for $8 \mathrm{~h}$ (ISO 659:2014) and the yield was $51.5 \%$ for pumpkin seeds, $41.6 \%$ for melon seeds and $49.1 \%$ for sunflower seeds. The obtained oils were subjected to heating (conventional and microwave) with different duration. The microwave heating was performed into two powers $600 \mathrm{~W}$ and $900 \mathrm{~W}$ for 3, 6, 9 and $12 \mathrm{~min}$ in a microwave oven (LG Model MS1907C). The conventional heating was performed on electric cooktop with 1 burner for 9, 12 and $18 \mathrm{~min}$.

All reagents used were purchased by Merck (KGaA, Darmstadt, Germany) and were with analytical grade.

\subsection{Physicochemical characteristics}

The physicochemical properties (acid and peroxide value) of the oils were analysed following the standard procedures by ISO (ISO 660:2009; ISO 3960:2017). The absorbance at 232 and $268 \mathrm{~nm}$ was determined using a Boeco S26 spectrophotometer after diluting the oil in isooctane $(1 / 100, \mathrm{v} / \mathrm{v})$ (ISO 3656:2011).

\subsection{Tocopherol composition}

Tocopherols and tocotrienols were determined directly in the oil by high performance liquid chromatography on a
Merck-Hitachi (Merck, Darmstadt, Germany) instrument equipped with $250 \times 4 \mathrm{~mm}$ Nucleosil Si 50-5 column and fluorescent detector Merck-Hitachi F 1000. The operating conditions were mobile phase of hexane: dioxane, 96:4 (v/v) and flow rate $1 \mathrm{~mL} / \mathrm{min}$, excitation $295 \mathrm{~nm}$, emission $330 \mathrm{~nm}$. $20 \mu \mathrm{L} 1 \%$ solution of crude oil in hexane were injected. Tocopherols and tocotrienols were identified by comparing the retention times with those of authentic individual ones. Reference individual pure tocopherols (DL- $\alpha-$, DL- $\beta-$, DL- $\gamma-$ and DL- $\delta$-tocopherols with purity $\geq 98 \%$ ) were purchased from Merck (Darmstadt, Germany) and Tocomin SupraBio was purchased from Carlson Laboratories, Inc. (Arlington Heights, IL, USA). The tocopherol content was calculated on the base of tocopherol peak areas in the sample vs. tocopherol peak area of standard tocopherol solution (ISO 9936:2016).

\subsection{Fatty acid composition}

Fatty acid composition of the examined glyceride oils was determined by gas chromatography (GC) (ISO 12966-1:2014). Fatty acid methyl esters (FAMEs) were prepared by transesterification of the oils with sulfuric acid in methanol (ISO 12966-2:2017). Determination of FAMEs was performed on HP 5890 gas chromatograph equipped with a $75 \times 0.18 \times 25$ $\mu \mathrm{m}$ (film thickness) capillary Supelco column $\left(\mathrm{SP}^{\mathrm{TM}}-2560\right.$, Fused silica Capillary Column) and a flame ionization detector. The column temperature was programmed from $140^{\circ} \mathrm{C}$ (hold $5 \mathrm{~min}$ ), at $4{ }^{\circ} \mathrm{C} / \mathrm{min}$ to $240^{\circ} \mathrm{C}$ (hold $3 \mathrm{~min}$ ); the injector and detector temperatures were set at $250{ }^{\circ} \mathrm{C}$. Identification was performed by comparison of the retention times with those of a standard mixture of FAME (Supelco, USA 37 comp. FAME mix) subjected to GC under identical experimental conditions.

\subsection{Statistical analysis}

All measurements were performed in triplicate $(n=3)$ and the results were presented as mean value with the corresponding standard deviation (SD). Significant differences were determined by an analysis of variance (Duncan test) with a significance level $p<0.05$ using IBM SPSS Statistics 19.

\section{Results and discussion}

\subsection{Physicochemical characteristics}

The measured temperatures of pumpkin, melon and sunflower oils after microwave and conventional heating are given in Table 1.

The temperature increases with increasing the duration of heating and the power of the microwaves $(p<0.05)$. Higher temperature values for conventional heating compared to the microwave once were observed even for the same duration of processing.

Reactive free radicals are formed during the heating, which rapidly interact with atmospheric oxygen to form hydroperoxides, and they can be determined with the peroxide value that depicts the degree of oil oxidation. The results about changes of the peroxide value of the pumpkin, melon and sunflower oils subjected to microwave and conventional heating are shown in Figure 1. 
Table 1. Temperatures $\left({ }^{\circ} \mathrm{C}\right)$ of pumpkin, melon and sunflower oils after conventional and microwave (MW) heating.

\begin{tabular}{|c|c|c|c|c|c|c|c|}
\hline Power of MW heating, W & \multicolumn{4}{|c|}{ Microwave } & \multicolumn{3}{|c|}{ Conventional } \\
\hline \multicolumn{8}{|c|}{ Temperatures $\left({ }^{\circ} \mathrm{C}\right)$ of pumpkin seed oil } \\
\hline 900 & $61 \pm 1^{\mathrm{e}}$ & $109 \pm 2^{\mathrm{f}}$ & $118 \pm 2^{\mathrm{g}}$ & $120 \pm 3^{\mathrm{h}}$ & $125 \pm 2^{\mathrm{i}}$ & $128 \pm 3^{\mathrm{j}}$ & $133 \pm 2^{\mathrm{k}}$ \\
\hline \multicolumn{8}{|c|}{ Temperatures $\left({ }^{\circ} \mathrm{C}\right)$ of melon seed oil } \\
\hline 600 & $64 \pm 1^{\mathrm{a}}$ & $82 \pm 2^{b}$ & $86 \pm 2^{\mathrm{c}}$ & $90 \pm 1^{\mathrm{d}}$ & $131 \pm 2^{\mathrm{i}}$ & $136 \pm 2^{\mathrm{j}}$ & $139 \pm 1^{\mathrm{k}}$ \\
\hline \multicolumn{8}{|c|}{ Temperatures $\left({ }^{\circ} \mathrm{C}\right)$ of sunflower oil } \\
\hline 600 & $66 \pm 2^{a}$ & $72 \pm 1^{\mathrm{a}}$ & $78 \pm 2^{\mathrm{c}}$ & $88 \pm 1^{\mathrm{e}}$ & \multirow[b]{2}{*}{$120 \pm 1^{\mathrm{g}}$} & \multirow{2}{*}{$131 \pm 2^{\mathrm{h}}$} & \multirow{2}{*}{$136 \pm 2^{i}$} \\
\hline 900 & $68 \pm 1^{\mathrm{b}}$ & $83 \pm 2^{b}$ & $85 \pm 3^{\mathrm{d}}$ & $102 \pm 2^{\mathrm{f}}$ & & & \\
\hline
\end{tabular}

Values are means $\pm \mathrm{SD}(n=3)$. Different letters in the same oil mean significant differences $(p<0.05)$ using Duncan test.

A)

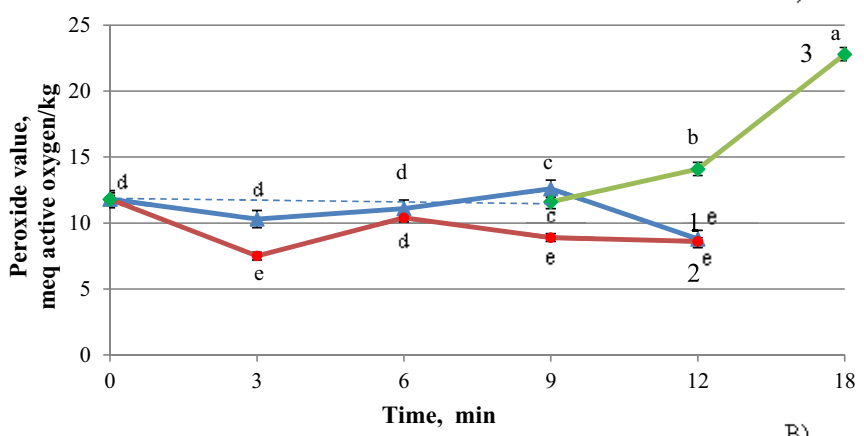

B)
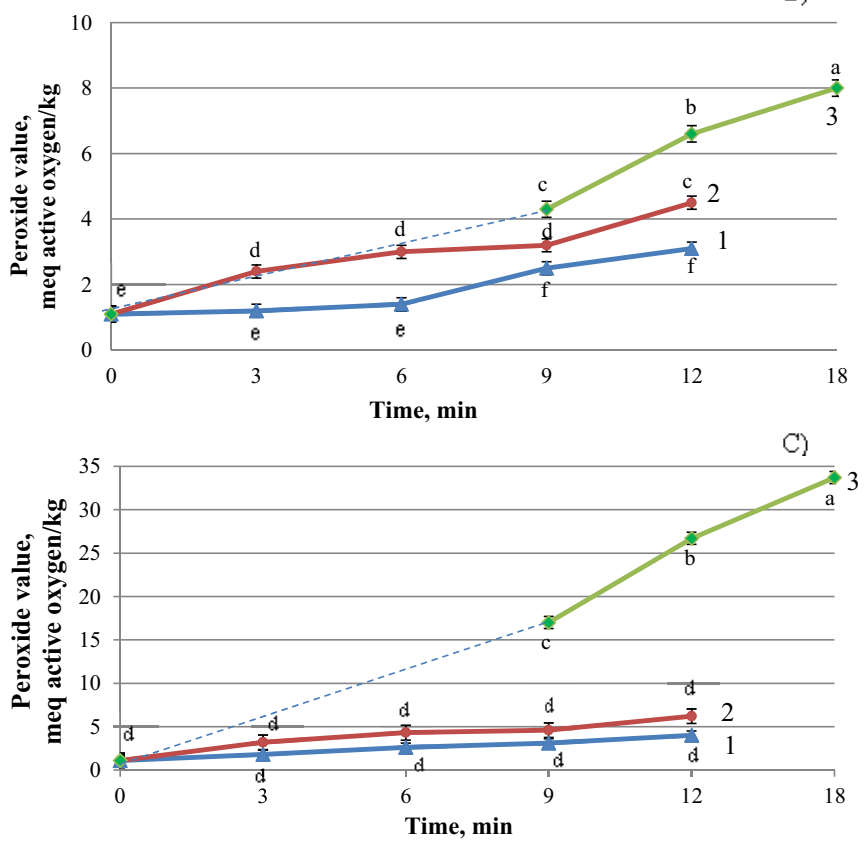

Fig. 1. Changes in the peroxide value of pumpkin (A), melon (B) and sunflower oils (C) subjected to heating: $1-600 \mathrm{~W}, 2-900 \mathrm{~W}$ and $3-$ conventional heating. Values are means $\pm \operatorname{SD}(n=3)$. ${ }^{*}$ Different letters in the same oil mean significant differences $(p<0.05)$ using Duncan test.

The peroxide value of the pumpkin seed oil decreased from 11.8 to $7.3-10.3 \mathrm{meq}$ active oxygen $/ \mathrm{kg}$ when was exposed to microwave heating for $3 \mathrm{~min}$, then increased in the period from
3 to $9 \mathrm{~min}$ and again decreased to 8.8 and $8.6 \mathrm{meq}$ active oxygen $/ \mathrm{kg}$ at $12 \mathrm{~min}$ of heating (Fig. 1A). Their lower values in the studied periods can be explained by the fact that the primary products of the oxidation are hydroperoxides, which are unstable and once formed, they easily can be converted into secondary oxidation products. Similar results were obtained by Vieira and Regitano-D'Arce (1998) who monitored the changes in the peroxide value of microwave heated canola, corn and soybean oils. The peroxide value of the oils was found to have a maximum at 4 and $6 \mathrm{~min}$, and then it decreased. In the canola oil, the peroxide value decreased at $6 \mathrm{~min}$ of heating, then increased at $20 \mathrm{~min}$ and after that was observed stabilization at $36 \mathrm{~min}$. The peroxide value of the pumpkin seed oil increased significantly after conventional heating (from 11.8 to 22.8 meq active oxygen $/ \mathrm{kg} ; p<0.05$ ).

The amount of hydroperoxides during microwave heating of melon and sunflower oils increased with an increase of the duration of heating and the power of the microwaves (Fig. 1B and $\mathrm{C}$ ). The maximum power $(900 \mathrm{~W})$ produced a larger amount of hydroperoxides compared to microwave heating at $600 \mathrm{~W}$. The peroxide value of the conventionally heated melon and sunflower oils increased considerably $(p<0.05)$, but the latter possessed a higher degree of oxidation (from 17.0 to $33.7 \mathrm{meq}$ active oxygen $/ \mathrm{kg}$ ). Melon seed oil had the lowest degree of oxidation after both microwave and conventional heating and its peroxide value met the requirements for this value for refined and unrefined vegetable oils (up to 10 and $15 \mathrm{meq}$ active oxygen $/ \mathrm{kg}$, respectively) (Codex-Stan 210:1999).

The peroxide values of the three examined oils after conventional heating are higher compared to the microwave one. Probably, the higher temperature and longer duration of the heating influence the oxidation process in the oils. The obtained results differed from these reported by Poiana (2012) according to whom the microwave heating accelerated the lipid oxidation at a higher degree than the conventional treatment.

The accumulation of hydroxides is also associated with the simultaneous formation of conjugated dienes and trienes structures with an absorption maximum in the range of 230 $234 \mathrm{~nm}$ and $265-270 \mathrm{~nm}$. The absorbance of the heated oils diluted in isooctane at 232 and $268 \mathrm{~nm}$ is shown in Table 2.

The rate of oxidation processes during conventional heating was higher (the increase in the absorption values 
Table 2. Changes in the absorbance of pumpkin, melon and sunflower oils at 232 and $268 \mathrm{~nm}$ after microwave (MW) and conventional heating.

\begin{tabular}{|c|c|c|c|c|c|c|c|c|c|}
\hline \multirow[t]{3}{*}{$\tau, \min$} & \multicolumn{3}{|c|}{ Pumpkin seed oil } & \multicolumn{3}{|c|}{ Melon seed oil } & \multicolumn{3}{|c|}{ Sunflower oil } \\
\hline & \multicolumn{2}{|c|}{ MW heating } & \multirow{2}{*}{$\begin{array}{l}\text { Conventional } \\
\text { heating }\end{array}$} & \multicolumn{2}{|c|}{ MW heating } & \multirow{2}{*}{$\begin{array}{l}\text { Conventional } \\
\text { heating }\end{array}$} & \multicolumn{2}{|c|}{ MW heating } & \multirow{2}{*}{$\begin{array}{l}\text { Conventional } \\
\text { heating }\end{array}$} \\
\hline & $600 \mathrm{~W}$ & $900 \mathrm{~W}$ & & $600 \mathrm{~W}$ & $900 \mathrm{~W}$ & & $600 \mathrm{~W}$ & $900 \mathrm{~W}$ & \\
\hline \multicolumn{10}{|l|}{$232 \mathrm{~nm}$} \\
\hline 0 & $0.937 \pm 0.017^{\mathrm{a}}$ & $0.937 \pm 0.017^{\mathrm{a}}$ & $0.937 \pm 0.017^{\mathrm{a}}$ & $3.050 \pm 0.050^{\mathrm{a}}$ & $3.050 \pm 0.050^{\mathrm{a}}$ & $3.050 \pm 0.050^{\mathrm{a}}$ & $0.996 \pm 0.008^{\mathrm{a}}$ & $0.996 \pm 0.008^{\mathrm{a}}$ & $0.996 \pm 0.008^{\mathrm{a}}$ \\
\hline 3 & $1.053 \pm 0.010^{\mathrm{b}}$ & $1.150 \pm 0.015^{\mathrm{c}}$ & $-^{*}$ & $3.056 \pm 0.015^{\mathrm{b}}$ & $3.190 \pm 0.011^{\mathrm{c}}$ & - & $0.999 \pm 0.010^{\mathrm{bc}}$ & $1.010 \pm 0.010^{\mathrm{b}, \mathrm{c}}$ & - \\
\hline 12 & $1.142 \pm 0.005^{\mathrm{g}}$ & $1.339 \pm 0.010^{\mathrm{h}}$ & $1.588 \pm 0.010^{\mathrm{i}}$ & $3.256 \pm 0.020^{\mathrm{d}}$ & $3.244 \pm 0.014^{\mathrm{e}}$ & $3.356 \pm 0.008^{\mathrm{f}}$ & $1.054 \pm 0.007^{\mathrm{f}}$ & $1.066 \pm 0.005^{\mathrm{g}}$ & $1.456 \pm 0.015^{\mathrm{h}}$ \\
\hline 18 & - & - & $1.678 \pm 0.005^{\mathrm{j}}$ & - & - & $3.536 \pm 0.012^{\mathrm{g}}$ & - & - & $1.486 \pm 0.008^{\mathrm{i}}$ \\
\hline \multicolumn{10}{|c|}{$268 \mathrm{~nm}$} \\
\hline 0 & $0.406 \pm 0.006^{\mathrm{a}}$ & $0.406 \pm 0.006^{\mathrm{a}}$ & $0.406 \pm 0.006^{\mathrm{a}}$ & $1.604 \pm 0.008^{\mathrm{a}}$ & $1.604 \pm 0.008^{\mathrm{a}}$ & $1.604 \pm 0.008^{\mathrm{a}}$ & $0.181 \pm 0.004^{\mathrm{a}}$ & $0.181 \pm 0.004^{\mathrm{a}}$ & $0.181 \pm 0.004^{\mathrm{a}}$ \\
\hline 3 & $0.403 \pm 0.003^{\mathrm{a}}$ & $0.388 \pm 0.006^{\mathrm{a}}$ & - & $1.584 \pm 0.010^{\mathrm{b}}$ & $1.554 \pm 0.004^{\mathrm{c}}$ & - & $0.165 \pm 0.005^{\mathrm{a}}$ & $0.171 \pm 0.010^{\mathrm{a}}$ & - \\
\hline 6 & $0.407 \pm 0.007^{\mathrm{a}}$ & $0.391 \pm 0.005^{\mathrm{a}}$ & - & $1.608 \pm 0.008^{\mathrm{b}}$ & $1.556 \pm 0.009^{c}$ & - & $0.170 \pm 0.003^{\mathrm{a}}$ & $0.193 \pm 0.009^{\mathrm{a}}$ & - \\
\hline
\end{tabular}

Values are means $\pm \mathrm{SD}(n=3)$. Different letters in the same oil mean significant differences $(p<0.05)$ using Duncan test.

${ }^{*}$ No heating was performed at this period of time.

was about $70 \%$ for the pumpkin seed oil, $16 \%$ for the melon seed oil and $50 \%$ for the sunflower oil). The absorbance at $232 \mathrm{~nm}$ of the treated oil samples during microwave and conventional heating increased with the duration of the treatment and the power of microwaves. The microwave heating of melon and sunflower oils showed a minimal increase in absorbance at $232 \mathrm{~nm}$ - about 6-7\% compared to its initial value, while in pumpkin seed oil the growth was about $20-40 \%(p<0.05)$, indicating that the formation of conjugated dienes was accelerated.

Similar results were obtained in previous studies in which the thermal stability of rapeseed, sunflower, soybean, corn and canola oils were examined (Lukešova et al., 2009; Poiana, 2012; Vieira and Regitano-D'Arce, 1998). They showed that the microwave heating initiated lipid oxidation and the absorption at $232 \mathrm{~nm}$ increased due to the formation of conjugated dienes. It was also found that up to 10-12 min of heating sunflower, rapeseed, soybean and canola oils the change in the value of the absorption compared to that of the control sample was negligible, and then increased at the end of the thermal treatment.

The absorbance of the microwave heated pumpkin seed oil at $268 \mathrm{~nm}$ at medium and high microwave power had values close to the control oil (oil that was not processed thermally) (Table 2). The absorption of the pumpkin seed oil subjected to conventional heating increased and reached 0.573 at $18 \mathrm{~min}$ $(p<0.05)$. The values of absorption at $268 \mathrm{~nm}$ of microwave heated melon seed oil remained almost the same as the values of the control sample, while in the conventional heated oil was even lower than those of the control (Table 2). The absorption at this wavelength of microwave heated sunflower oil increased insignificantly with the duration of the heating, and the values were close to that of the control oil (Table 2). The absorption of sunflower oil increased about 2.5 times during conventional heating.
It was observed that the values of the absorption at $268 \mathrm{~nm}$ of conventionally heated sunflower and pumpkin oils were relatively high, while the changes of the values of microwave heated oils were negligible. These results showed a higher oxidative stability of melon oil at both thermal treatments, while pumpkin and sunflower oils were more stable when exposed to microwave heating.

The obtained results were in agreement with these reported by Vieira and Regitano-D'Arce (1998), who established that the absorption at $270 \mathrm{~nm}$ increased after microwave heating of canola, corn and soybean oils. The increase of the absorption were from $0.762(0 \mathrm{~min})$ to $1.163-1.445(12$ and $20 \mathrm{~min})$ for canola oil, from 1.587 to $2.096-2.527$ (12 and $20 \mathrm{~min}$ ) for corn oil and from 3.324 to $3.784-3.875$ (12 and $20 \mathrm{~min}$ ) for soybean oil, which depicted the formation of conjugated trienes in the oils.

Acid value (an indicator for the amount of the free fatty acids in the oils) of the pumpkin, melon and sunflower oils, that are conventionally and microwave heated, are shown in Table 3 .

The acid value of pumpkin seed oil slightly increased when the time of microwave and conventional heating was extended and the power of the microwaves was increased. The acid value of the conventionally heated pumpkin seed oil was slightly lower, which indicated that during the microwave heating were produced more free fatty acids.

The acid values of microwave and conventionally heated melon and sunflower oils had the same values as the control oil, hence the thermal treatment of these oils did not initiate the formation of free fatty acids.

The obtained results differed from these reported by Vieira and Regitano-D'Arce (1998), who observed that the content of the free fatty acids increased after microwave treatment of corn oil - from 0.077 to $0.127-0.129 \%$ (12 and $20 \mathrm{~min}$ ); and for soybean oil - from 0.075 to $0.107-0.132 \%$ (12 and $20 \mathrm{~min}$ ). 
Table 3. Changes in the acid value ( $\mathrm{mg} \mathrm{KOH} / \mathrm{g}$ ) of pumpkin, melon and sunflower oils subjected to microwave (MW) and conventional heating.

\begin{tabular}{|c|c|c|c|c|c|c|c|c|}
\hline Power of MW heating, W & Control oils $(0 \mathrm{~min})$ & \multicolumn{4}{|c|}{ Microwave heating } & \multicolumn{3}{|c|}{ Conventional heating } \\
\hline & Pumpkin seed oil & & & & & \multirow[b]{3}{*}{$4.0 \pm 0.3^{b}$} & \multirow[b]{3}{*}{$4.1 \pm 0.2^{b}$} & \multirow{3}{*}{$4.1 \pm 0.3^{\mathrm{a}, \mathrm{t}}$} \\
\hline 600 & $3.7 \pm 0.2^{\mathrm{a}}$ & $3.9 \pm 0.2^{\mathrm{a}, \mathrm{b}}$ & $4.0 \pm 0.1^{\mathrm{a}, \mathrm{b}}$ & $4.3 \pm 0.3^{\mathrm{b}}$ & $4.4 \pm 0.2^{\mathrm{b}}$ & & & \\
\hline 900 & $\begin{array}{l}3.7 \pm 0.2^{\mathrm{a}} \\
\text { Melon seed oil }\end{array}$ & $4.0 \pm 0.2^{\mathrm{a}, \mathrm{b}}$ & $4.3 \pm 0.3^{\mathrm{a}, \mathrm{b}}$ & $4.4 \pm 0.1^{\mathrm{b}}$ & $4.6 \pm 0.2^{b}$ & & & \\
\hline 600 & $0.3 \pm 0.1^{\mathrm{d}}$ & $0.3 \pm 0.0^{\mathrm{d}}$ & $0.3 \pm 0.1^{\mathrm{d}}$ & $0.3 \pm 0.1^{\mathrm{d}}$ & $0.3 \pm 0.0^{\mathrm{d}}$ & \multirow{2}{*}{$0.3 \pm 0.0^{\mathrm{d}}$} & \multirow{2}{*}{$0.3 \pm 0.1^{\mathrm{d}}$} & \multirow{2}{*}{$0.3 \pm 0.1^{\mathrm{d}}$} \\
\hline 900 & $0.3 \pm 0.1^{\mathrm{d}}$ & $0.3 \pm 0.1^{\mathrm{d}}$ & $0.3 \pm 0.1^{\mathrm{d}}$ & $0.3 \pm 0.0^{\mathrm{d}}$ & $0.3 \pm 0.0^{\mathrm{d}}$ & & & \\
\hline
\end{tabular}

Values are means $\pm \mathrm{SD}(n=3)$. Different letters in the same oil mean significant differences $(p<0.05)$ using Duncan test.

\subsection{Tocopherol composition}

The changes in the total tocopherol content of the pumpkin, melon and sunflower oils, subjected to microwave and conventional heating are shown in Figure 2A-C.

Total content of tocopherols decreased with increasing the time of microwave and conventional heating. They decreased from 983 to $566 \mathrm{mg} / \mathrm{kg}$ during microwave heating of pumpkin seed oil at $600 \mathrm{~W}$, and from 983 to $546 \mathrm{mg} / \mathrm{kg}$ at $900 \mathrm{~W}$ $(p<0.05)$. During the conventional heating of the same oil, the tocopherols decreased to about $700 \mathrm{mg} / \mathrm{kg}$ after $9-12 \mathrm{~min}$ treatment of the sample, and then their amount sharply decreased to $437 \mathrm{mg} / \mathrm{kg}$ at $18 \mathrm{~min}(p<0.05)$.

When melon seed oil was heated, the changes of total tocopherol content were minimal, both in the microwave (from 884 to $827 \mathrm{mg} / \mathrm{kg}$ at $12 \mathrm{~min}$ ) and the conventional heating (from 884 to $701 \mathrm{mg} / \mathrm{kg}$ at $18 \mathrm{~min}$ ).

The changes of tocopherol content of sunflower oil subjected to microwave heating was minimal (from 677 to $624 \mathrm{mg} / \mathrm{kg}$ ), whereas in the case of conventional heating the amount of tocopherols decreased sharply after 9 min of heating of the oil - from 548 to $312 \mathrm{mg} / \mathrm{kg}(p<0.05)$.

The degradation of the tocopherols was to a lesser extent in the microwave and conventionally heated melon seed oil and in the sunflower oil subjected to microwave heating. Total tocopherols were reduced with $50 \%$ during the conventional heating of pumpkin and sunflower oils at $18 \mathrm{~min}$. Considerably better preservation of the tocopherols after the microwave treatment was established and it was most likely due to the shorter time of the microwave heating. Yoshida et al. (1991, 1992) also established that prolonging the heating time affected total tocopherol content which amount decreased. According to these authors, a higher content of saturated fatty acids in the oils produces a larger amount of free fatty acids that have a destructive effect on tocopherols.

The unsaturated fatty acids predominated in the studied oils and the amount of free fatty acids in them was minimal so their impact on the destruction of tocopherols was smaller. Changes in the individual tocopherol composition of pumpkin, melon and sunflower oils subjected to microwave and conventional heating are presented in Table 4.

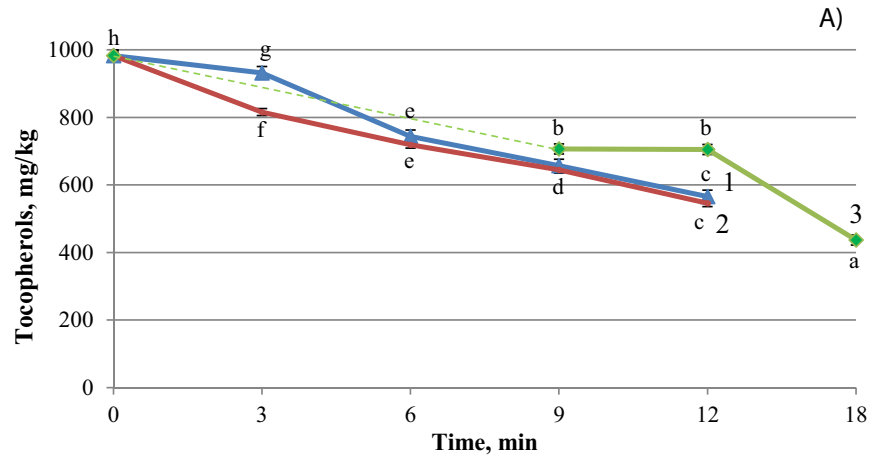

B)

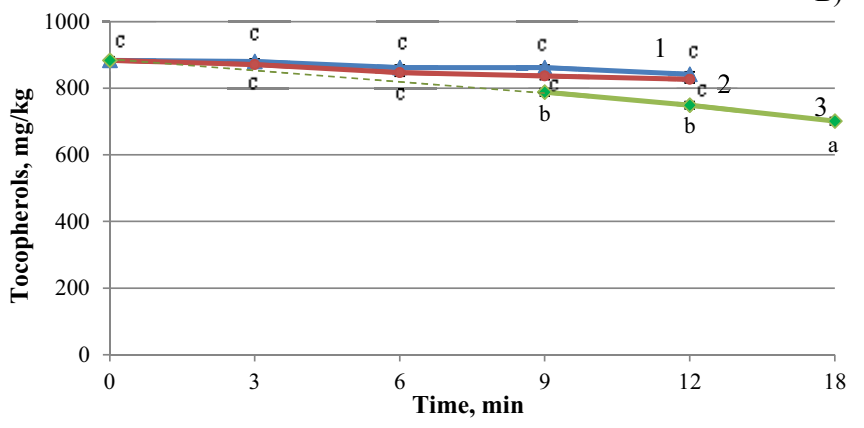

C)

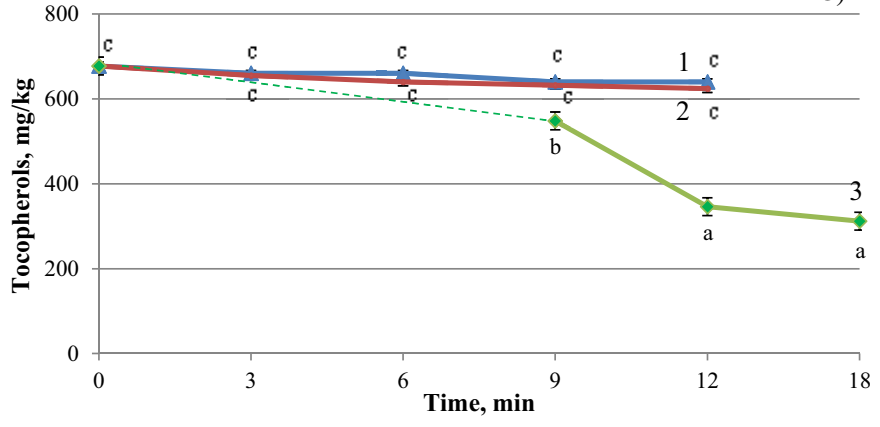

Fig. 2. Changes in total tocopherol content of pumpkin (A), melon (B) and sunflower oils (C) subjected to heating: 1-600W, $2-900 \mathrm{~W}$ and 3 - conventional heating. Values are means $\pm \mathrm{SD}(n=3)$. Different letters in the same oil mean significant differences $(p<0.05)$ using Duncan test. 
Table 4. Changes in the tocopherol composition of pumpkin, melon and sunflower oils during microwave and conventional heating.

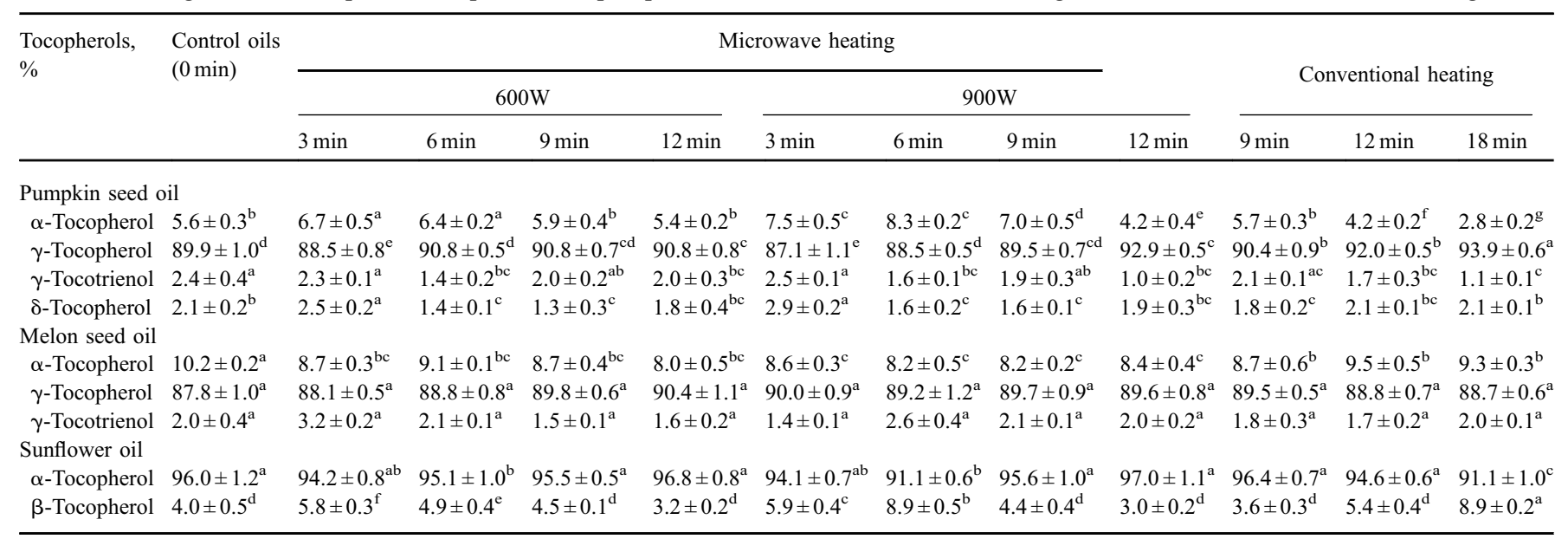

Values are means $\pm \mathrm{SD}(n=3)$. Different letters in the same line mean significant differences $(p<0.05)$ using Duncan test.

The qualitative tocopherol composition of the tested oils was preserved during the thermal heating and minor quantitative changes were observed. The amount of $\alpha$-tocopherol in pumpkin seed oil insignificantly increased after $9 \mathrm{~min}$ of microwave heating, but after that decreased up to $4.2 \%$ ( $12 \mathrm{~min}$ at $900 \mathrm{~W}$ ). A considerable decrease of $\alpha$-tocopherol (from 5.6 to $2.8 \%$ ) was observed after conventional heating of the same oil $(p<0.05)$, while in melon seed oil the reduction of $\alpha$-tocopherol was minor. The quantity of $\alpha$-tocopherol in sunflower oil insignificantly decreased after microwave heating up to 9 min and after that increased (up to $96 \%$ ), while during the conventional heating its amount slightly decreased up to $91.1 \%$ at the expense of the content of $\beta$-tocopherol.

It was found that during microwave heating tocopherols are much more stable in oils which contained more unsaturated fatty acids than saturated, therefore no significant changes in the tocopherol composition of the examined oils were observed.

\subsection{Fatty acid composition}

Fatty acids containing $8-20$ carbon atoms $\left(\mathrm{C}_{8}-\mathrm{C}_{20}\right)$ were identified in all examined oils. In the control pumpkin seed oil were identified 10 fatty acids, in melon seed oil -15 , and in sunflower oil -8 . The composition of the oils predominantly consisted of linoleic, oleic, palmitic and stearic acids. Their content was as follows: linoleic (40.0, 54.6 and 51.8\%, respectively), oleic (35.1, 20.7 and $35.5 \%$ ), and palmitic (18.4, 15.1 and $12.1 \%$ ), while those of stearic was found to be lower $(5.9,7.4$ and $3.5 \%)$. The other fatty acids were present in small amounts up to $0.4 \%$. The obtained results were in agreement with these reported by previous authors (Kim et al., 2012; Yanty et al., 2008; Petkova and Antova, 2015; Rabrenović et al., 2014; Codex-Stan 210:1999).

Fatty acid composition of pumpkin, melon and sunflower oils subjected to microwave and conventional heating was close to that of the control oils and main changes were observed in the quantity of the major fatty acids (Fig. 3).

Microwave heating of the pumpkin seed oil at 600 and $900 \mathrm{~W}$ caused an increase in the amount of palmitic acid from
18.4 to $22.1 \%$, whereas during conventional heating the change in its quantity was not significant (from 18.4 to $16.5 \%$ ). The amount of stearic acid decreased during microwave heating at $600 \mathrm{~W}$, while at maximum power and conventional heating - the amount of the same acid was close to that of the control oil. Reducing the quantity of linoleic acid (from 40.0 to $23.3 \%$ ) was at a greater extent during microwave heating at $900 \mathrm{~W}$ compared to $600 \mathrm{~W}$ (from 40.0 to $37.7 \%$ ). Therefore, microwave heating at a maximum power caused the greatest change in the composition of the pumpkin seed oil. The changes of the major fatty acids (oleic, linoleic, palmitic and stearic) of this oil after conventional heating were insignificant, i.e. their amount remained the same as in the control sample.

The microwave heating of melon seed oil caused an insignificant decrease in the amount of palmitic acid from 15.1 to $13.1 \%(600 \mathrm{~W}, 3 \mathrm{~min})$ and $11.6 \%(900 \mathrm{~W}, 3 \mathrm{~min})$, then within 12 min reached the initial amount (about $15.0 \%$ ). The quantity of stearic acid maintained unchanged during microwave heating, and those of linoleic acid increased significantly at $3 \mathrm{~min}$. The amount of palmitic and stearic acids after conventional heating of the oil were changed insignificantly (decreased from 15.1 to $9.7 \%$ and from 7.4 to $3.9 \%$ at $3 \mathrm{~min}$, respectively, then slightly increased to 11.1 and $4.4 \%$ ), while the quantity of linoleic acid significantly increased from 54.6 to $71.3-68.7 \%$. It was established that the duration of thermal treatment of melon seed oil had no significant impact on the fatty acid composition.

The changes in the content of palmitic acid during microwave and conventional heating of sunflower oil were not significant, except at $900 \mathrm{~W}$ of microwave heating at $3 \mathrm{~min}$, where its quantity increased from 8.8 to $16.0 \%$. The amount of stearic acid significantly increased after microwave heating at maximum power $(900 \mathrm{~W})$, whereas in the case of conventional and microwave heating at $600 \mathrm{~W}$ its quantity was close to that of the control oil. The content of linoleic acid decreased during microwave heating (from 51.8 to $35.6 \%$ ), while those of oleic acid increased (from 35.5 to $46.6 \%$ ), and a higher change was observed at $900 \mathrm{~W}$ power of the microwaves. There were no noticeable changes in the fatty composition of sunflower oil during conventional heating. 

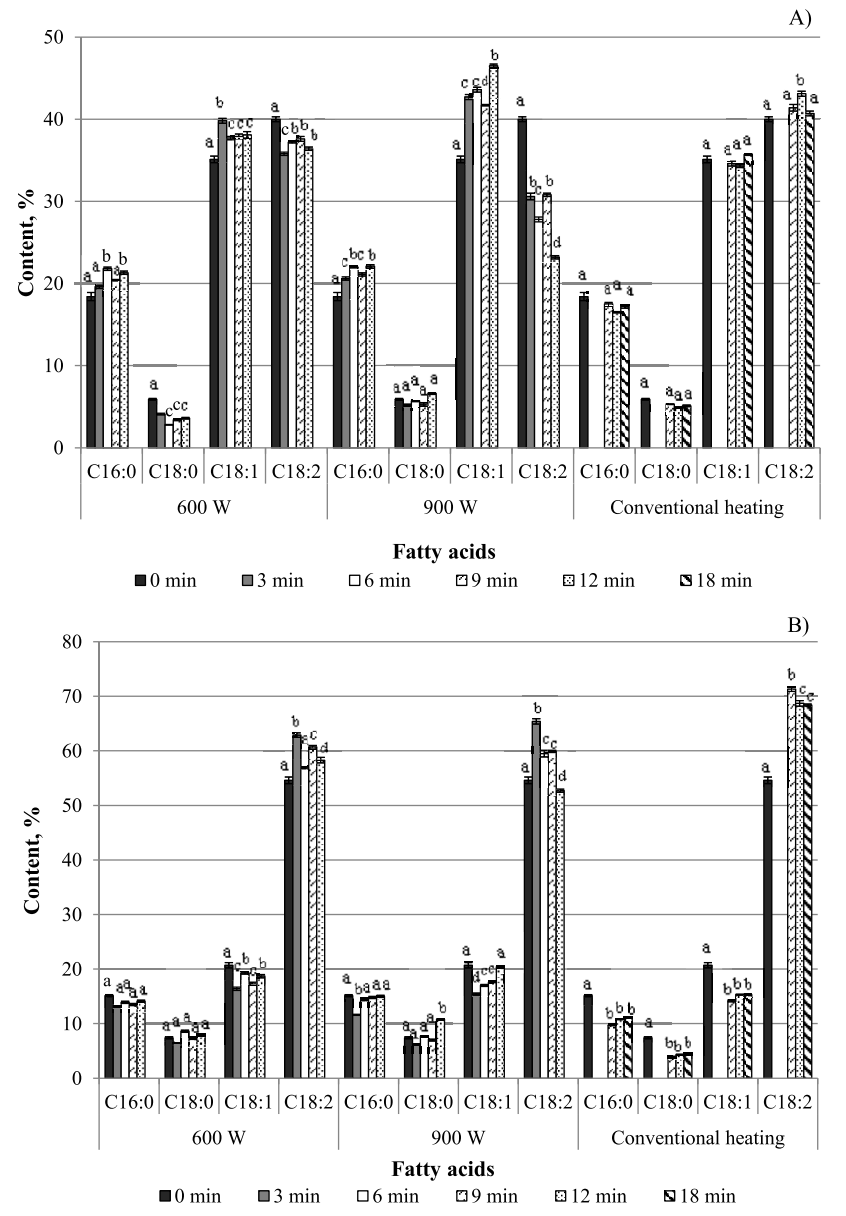

C)

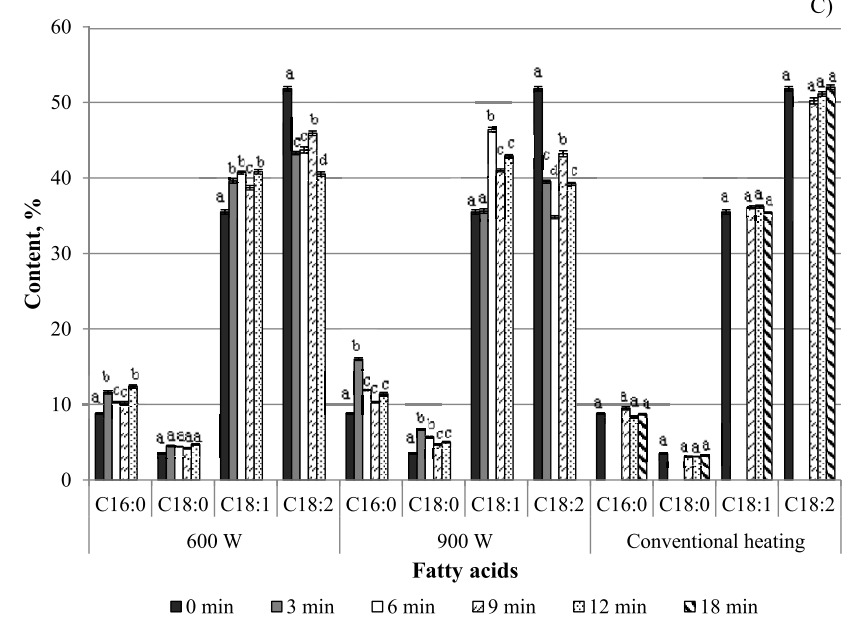

Fig. 3. Changes of the main fatty acids of pumpkin (A), melon (B) and sunflower oils (C) subjected to microwave $(600 \mathrm{~W}$ and $900 \mathrm{~W})$ and conventional heating. ${ }^{*}$ Different letters in the same fatty acid mean significant differences $(p<0.05)$ using Duncan test. ${ }^{* *} \mathrm{C}{ }_{16: 0^{-}}$ Palmitic; C 18:0-Stearic; C ${ }_{18: 1}$-Oleic; C ${ }_{18: 2}$-Linoleic. Values are means $\pm \mathrm{SD}(n=3)$.

The greatest changes in the fatty acid composition were observed in pumpkin and sunflower oils, while in melon seed oil, there were no significant changes in the main fatty acids. The decrease of the amount of unsaturated fatty acids in the thermally treated pumpkin and sunflower oils was at the expense of the increase of the content of saturated fatty acids and this could be explained with the reactions described by Farag et al. (1992). The authors reported that oxidative degradation and production of short-chain acids were observed during microwave and conventional heating of oils. According to Yoshida et al. (1991), tocopherols are more stable during microwave heating in the longer fatty acids than they are in the shorter ones. The decrease of total tocopherols in melon seed oil during heating was minimal and probably related to the preservation of linoleic acid in the oil. On the other hand, the changes in peroxide value of thermally treated melon seed oil was lower than these depicted in Codex-Stan (1999) (10 $15 \mathrm{meq}$ active oxygen $/ \mathrm{kg}$ ) which lead to formation of less amount of hydroperoxides that decomposes longer unsaturated fatty acids (Yoshida et al., 1991). Therefore, the variations in the main fatty acids of thermally treated melon seed oil were negligible.

\section{Conclusion}

The present study was first to monitor the changes that occurred in quality parameters (acid, peroxide value, absorbance at $232,268 \mathrm{~nm}$, tocopherol and fatty acid composition) of pumpkin and melon seed oils during conventional and microwave treatment and were compared to these of sunflower oil.

The degree of oxidation of pumpkin, melon and sunflower oils during microwave and conventional heating increases with the duration of the thermal process and the power of the microwaves. Conventional heating causes acceleration of the lipid oxidation. The highest thermal stability is observed in melon seed oil for all types of heat treatment, while pumpkin and sunflower oils are more stable during microwave heating. The thermal treatment of the oils has a little impact on the processes leading to the formation of free fatty acids.

The microwave heating has a little impact on decreasing the content of tocopherols compared to conventional heating. Total tocopherols of melon seed oil seem to be more stable to thermal treatment (microwave and conventional). There are no considerable changes in the tocopherol composition of the examined oils during heating.

The decrease of the quantity of linoleic acid in pumpkin and sunflower oils during microwave heating was at the expense of the increase of the content of saturated palmitic acid. The biggest change in the fatty acid composition of both oils is found during microwave heating at $900 \mathrm{~W}$. The changes in fatty acid composition of thermally treated melon seed oil were insignificant. Overall, melon seed oil was observed to be more thermally stable than pumpkin and sunflower oils.

Acknowledgments. This study was partly supported by National programme "Young Scientists and Postdoctoral Students", Ministry of Education and Science, Bulgaria.

Conflicts of interest. The authors declare that they have no conflicts of interest in relation to this article.

\section{References}

Aktas N, Gerçekaslan KE, Uzlasır T. 2018. The effect of some preroasting treatments on quality charactersirics of pumpkin seed oil. Oilseeds Fats Crops Lipids 25: 2-10. DOI: 10.1051/oc1/2018025. 
AOAC - Association of Official Analytical Chemist. 2016. Official methods of analysis, 20th edn. Washington, DC.

Azhari S, Xu YS, Jiang QX, Xia WS. 2014. Physicochemical properties and chemical composition of Seinat (Cucumis melo var. tibish) seed oil and its antioxidant activity. Grasas Aceites 65 (1): e008. DOI: $10.3989 /$ gya.074913.

Codex standard for named vegetable oils, Codex-Stan 210-1999. Revisions 2001, 2003, 2009, Amendment 2005, 2011, p. 16.

Farag RS, Hewedi FM, Abi-Raiia SH, EL-Baroty GS. 1992. Comparative study on the deterioration of oils by microwave and conventional heating. J Food Prot 55: 722-727. DOI: 10.4315/0362-028X-55.9.722.

Hassanein MM, El-Shami SM, El-Mallah MH. 2003. Changes occurring in vegetable oils composition due to microwave heating. Grasas Aceites 54: 343-349. DOI: 10.3989/gya.2003.v54.i4.219.

ISO 12966-1:2014. Animal and vegetable fats and oils. Gas chromatography of fatty acid methyl esters - Part 1: guidelines on modern gas chromatography of fatty acid methyl esters.

ISO 12966-2:2017. Animal and vegetable fat and oils. Gas chromatography of fatty acid methyl esters - Part 2: preparation of methyl esters of fatty acids.

ISO 3656:2011. Animal and vegetable fats and oils. Determination of ultraviolet absorbance expressed as specific UV extinction.

ISO 3960:2017. Animal and vegetable fats and oils. Determination of peroxide value. Iodometric (visual) endpoint determination.

ISO 659:2014. Oilseeds. Determination of oil content (reference method.

ISO 660:2009. Animal and vegetable fats and oils. Determination of acid value and acidity.

ISO 9936:2016. Animal and vegetable fats and oils. Determination of tocopherol and tocotrienol contents by high-performance liquid chromatography.

Jiao J, Zhu-Gang L, Qing-Yan G, Xiao-Juan L, Fu-Yao W, Yu-Jie F, Wei M. 2014. Microwave-assisted aqueous enzymatic extraction of oil from pumpkin seeds and evaluation of its physicochemical properties, fatty acid compositions and antioxidant activities. Food Chem 147: 17-24. DOI: 10.1016/j.foodchem.2013.09.079.

Kim MY, Kim EJ, Kim YN, Choi C, Lee BH. 2012. Comparison of the chemical compositions and nutritive values of various pumpkin (Cucurbitaceae) species and parts. Nutr Res Pract 6 (1): 21-27. DOI: 10.4162/nrp.2012.6.1.21.

Lukešova D, Dostálová J, El-Moneim Mahmoud E, Svárovská M. 2009. Oxidation changes of vegetable oils during microwave heating. Czech J Food Sci 27: 178-181.

Mariod A, Matthäus B. 2008. Fatty acids, tocopherols, sterols, phenolic profiles and oxidative stability of Cucumis melo var.
Agrestis oil. J Food Lipids 15(1): 56-67. DOI: 10.1111/ j.1745-4522.2007.00102.x.

Murkovic M, Piironen V, Lampi AM, Kraushofer T, Sontag G. 2004. Changes in chemical composition of pumpkin seeds during the roasting process for production of pumpkin seed oil (part 1: nonvolatile compounds). Food Chem 84: 359-365. DOI: 10.1016/ S0308-8146(03)00240-1.

Petkova Z, Antova G. 2015. Proximate composition of seeds and seed oils from melon (Cucumis melo L.) cultivated in Bulgaria. Cogent Food Agric 1: 1. DOI: 10.1080/23311932.2015.1018779.

Poiana MA. 2012. Enhancing oxidative stability of sunflower oil during convective and microwave heating using grape seed extract. Int J Mol Sci 13: 9240-9259. DOI: 10.3390/ ijms13079240.

Rabrenović BB, Dimić EB, Novaković MM, Tešević VV, Basić ZN 2014. The most important bioactive components of cold pressed oil from different pumpkin (Cucurbita pepo L.) seeds. LWT Food Sci Technol 55: 521-527. DOI: 10.1016/j.lwt.2013.10.019.

Szterk A, Roszko M, Sosińska E, Derewiaka D, Lewicki P. 2010. Chemical composition and oxidative stability of selected plant oils. J Am Oil Chem Soc 87(6): 637-645. DOI: 10.1007/ s11746-009-1539-4.

Vidrih R, Vidakovič S, Abramovič H. 2010. Biochemical parameters and oxidative resistance to thermal treatment of refined and unrefined vegetable edible oils. Czech J Food Sci 28: 376-384.

Vieira TMFS, Regitano-D'Arce MAB. 1998. Stability of oils heated by microwave: UV - spectrophotometric evaluation. Food Sci Technol 18: 433-437. DOI: 10.1590/S0101-20611998000400015.

Yanty NAM, Lai OM, Osman A, Long K, Ghazali HM. 2008. Physicochemical properties of Cucumis melo var. Inodorus (Honeydew melon) seed and seed oil. J Food Lipids 15(1): 42-55. DOI: $10.1111 /$ j.1745-4522.2007.00101.x.

Yoshida H, Kajimoto G. 1989. Effects of microwave energy on the tocopherols of soybean seeds. J Food Sci 54: 1596-1600. DOI: 10.1111/j.1365-2621.1989.tb05168.x.

Yoshida H, Nobuhisa H, Kajimoto G. 1990. Microwave energy effects on quality of some seed oils. J Food Sci 55: 1412-1416. DOI: 10.1111/j.1365-2621.1990.tb03947.x.

Yoshida H, Tatsumi M, Kajimoto G. 1991. Relationship between oxidative stability of Vitamin $\mathrm{E}$ and production of fatty acids in oils during microwave heating. J Am Oil Chem Soc 68: 566-570. DOI: $10.1007 / \mathrm{BF} 02660151$.

Yoshida H, Tatsumi M, Kajimoto G. 1992. Influence of fatty acids on the tocopherol stability in vegetable oils during microwave heating. J Am Oil Chem Soc 69: 119-125. DOI: 10.1007/ BF02540560.

Cite this article as: Petkova Z, Antova G. 2019. A comparative study on quality parameters of pumpkin, melon and sunflower oils during thermal treatment. $O C L$ 26: 32 . 